$\xi=$

\title{
Impact of counseling on cervical cancer and its screening on women knowledge, health beliefs and protective practices
}

\author{
Hoda AbedelAzim Mohamed ${ }^{1 *}$, Yosria El-sayed Hossein ${ }^{2}$ \\ ${ }^{1}$ Woman Health and Obstetric Nursing Department, Faculty of Nursing, Minia University, Minia, Egypt \\ ${ }^{2}$ Community Health Nursing Department, Faculty of Nursing, Minia University, Minia, Egypt \\ *Corresponding author E-mail:
}

\begin{abstract}
Background: Cervical cancer can be preventable or detected early especially with a series of regular screening with Pap tests. Aim of the study: The aim of this study were to evaluate the impact of counseling on cervical cancer and its screening on women knowledge, health beliefs and protective practices.

Subjects and Methods: A quasi-experimental design was used. A convenient ample of 120 women were randomly divided into experimental and control groups, each group consisted of 60 women were recruited from outpatient clinic at Obstetrics and Gynecology Department at Minia General Hospital.

Results It can be observed that, $86 \%$ of the women in the intervention group had good knowledge compared to only $17 \%$ of the control group and the difference is statistically significant. The mean score of perceived susceptibility and barriers in both groups was reduced but the decrease was significantly higher in the intervention group $(\mathrm{P}<0.004)$. The mean score of perceived severity and benefits in both groups were increased, but the increased mean score in the intervention group was higher. A highly statistical significant difference was observed between groups regarding protective practices $(\mathrm{p}=.001)$.

Conclusion: It can be concluded that there was a highly statistical significant improvement in women knowledge was observed and the higher positive beliefs about perceived benefits of preventive health practices, susceptibility, severity, health motivation and reduced the barriers of pap smear this can influence women's willingness to take preventive test and higher participation in regular Pap smear test in the intervention group. The most commonly barriers to screening cited in our study are lack of knowledge.

Recommendations: on the light of this findings it is recommended that, women should be encouraged to take responsibility for their own health and be active participants in the screening program, More educational intervention is needed to encourage adherence to routine cancer screening with raising women's awareness about cervical cancer, The barriers to Pap smear test are considered by the health authorities in order to overcome barriers of cervical cancer screening.
\end{abstract}

Keywords: Cervical Cancer; Health Beliefs; Pap smear test.

\section{Introduction}

Cervical cancer is the second most common cancer in women worldwide with an estimate of 440,000 new cases annually, and $80 \%$ of these cases occurring in developing and undeveloped countries due to inadequate use of the screening services. (Wong LP, 2009, Reis N, 2012).More than 270, 000 women die from cervical cancer every year, more than $85 \%$ of these deaths are in low and middle income countries, main cause of this problem is poor access to screening and treatment services (World Health Organization, 2013a).

Cervical cancer has a long pre malignant period that provides the opportunity for screen, easily diagnosed 10 to 15 years and treat before it turns to be invasive cervical malignancy (Khodakarami et al., 2013). Due to the long-term situation before the invasion, the cervical cancer is regarded as a preventable cancer, and with the early diagnosis and treatment, the invasive cervical cancers can be prevented (Ghahramaninasab et al., 2011).

American Cancer Society (2013) cited that screening is the test that is used to find a disease, in this instance, cervical cancer is usually done in individuals who do not have any symptoms of the disease. Cervical cancer screening tests and examinations usually offer best chances in detecting cervical cancer at a stage when it can be cured or treated successfully with a degree of relative ease. Screening actually prevent most cervical cancer due to the fact that it can successfully find pre cancer and these can easily be treated at an early stage before they can regenerate into cervical cancer cells. Cervical cancer can be preventable or detected early especially with a series of regular screening with Pap tests. Pap smear test is a convenient and inexpensive (Coskun et al., 2013). Human papilloma virus (HPV) infection is the biggest risk factor for cervical cancer, as the virus is present in $99 \%$ of cases worldwide, and it is related to $80 \%$ of precancerous changes in the cervix (Wong LP,2009). American College of Obstetricians and Gynaecologists (ACOG) suggested the Pap smear for women at the age of 21 years old, or 3 years after the beginning of vaginal sexual activity. The screening interval is once a year, and after the age of 30 , in case of three consecutive tests are normal, it is suggested once for every 2-3 years (Gacia, et al., 2012).Other risk factors for cervical cancer, including early onset of sexual activity at young age, over-aged pregnancy risk, lack of genital hygiene, null parity and multi-parity, alcohol and tobacco use, obesity, HIV infection, Prolonged use of oral contraceptive and Positive family history for 
cervical cancer (Zarchi et al., 2009; Arabaci and Ozsoy, 2012; Getahun et al., 2013; Matthews et al., 2013).

One of the main causes of the high prevalence of poor up taking of screening in the developing world is lack of awareness; therefore providing information on cervical cancer has an important role to influence the behaviour of target population (Nessa et al., 2012). Another ways for prevention of cervical cancer is the HPV vaccine. Vaccination can cause immunity both directly and indirectly through herd immunity (Khatibi et al., 2014).Limiting the number of sexual partners, avoiding or quitting smoking and minimizing exposure to environmental tobacco and consuming diet rich in fresh vegetables and fruits may help reduce the risk of cervical cancer. Health promotion activities on sexual health, smoking cessations and healthy diet can contribute to the prevention of cervical cancer. Early detection and treatment of cervical cancer through screening programs significantly reduce the morbidity and mortality of these diseases (Reis et al., 2012).

Another important factor that affects applications for early diagnosis of cervical cancer is women's belief. The Health Belief Model (HBM) is a model developed to understand human behaviour toward seeking health services and explain why people did not engage in behaviours for prevention or early detection of disease (Farooqui et al., 2013). The HBM explain that before undergoing screening, a person must believe that the problem is serious, that he/she is susceptible to the problem and that an effective action is available. Furthermore, the individual must believe that a particular action would be a beneficial in reducing susceptibility or the perceived severity, and the person must believe that the barriers to taking action will be outweighed by the benefits and that she must receive some sort of a cue to action.For the screening methods to be fully utilized, women need to be aware of the availability of the methods, to have knowledge of the disease and screening methods. These will enhance uptake of the screening for pre malignant lesions and hence reduction of morbidities and mortalities resulting from cervical cancer.

The rural population, due to the traditional practices such as frequent early marriage, less education, and insufficient health awareness requires more training for the cervical cancer screening (Elamurugan et al., 2016).In a study in the rural areas in India, the cognitive barriers such as low awareness of the cervical cancer symptoms, lack of information for the screening tests and risk factors of the cancer, were the most important obstacles of the rural women for preventive testing (Tripathi et al., 2014).Increase in diagnosis of the cases at the pre-invasive and early stages of cervical cancer led to the decrease in incidence and mortality rate of cervical cancer in the communities with active screening programs (Abedian\& Darmohamadi, 2015; Kasmaeiet al., 2014)

The health workers and midwives, due to their various health care, educational, counselling, and supportive roles, have great opportunities in preventing and improving the family health with important role in the intervention of women's health (Jamshidimanesh et al., 2013).

\subsection{Significance of the problem}

Egypt has a population of 30.55 million women ages15years and older who are at risk of developing cervical cancer. Current estimates indicate that every year 866 women are diagnosed with cervical cancer and 373 die from the disease. Cervical cancer ranks as the13 the most frequent cancer among women in Egypt and the10the most frequent cancer among women between 15 and 44 years of age

Although an intensive screening program for cervicalcanceriswellestablishedthroughHPVvac-

cine,andtheavailabilityofthePapsmeartestamongdifferenthealth sectors, most women in present-day at advanced stages that require extensive chemo-radiation therapy. considering the importance of Pap smear test in the early diagnosis of cervical cancer, the preventive interventions, seem to be essential. It is manda- tory to address the knowledge, beliefs and practices of the women about cervical cancer screening.

\subsection{Aim of the study}

To evaluate the impact of counselling on cervical cancer and its screening on women knowledge, health beliefs and protective practices.

\subsection{Research hypotheses}

- Women's knowledge regarding cervical cancer and its screening means score will be significantly higher post counseling.

- Counseling will be aid to change the false beliefs and enhance health practice for screening of cervical cancer.

\section{Subjects and methods}

\subsection{Research design}

A quasi-experimental (pre \& post) design was used.

\subsection{Setting}

This study was conducted in the outpatient clinic at Obstetrics and Gynaecology Department at Minia General Hospital which is affiliated to the Ministry of Health and Population (MOHP).It provide free services for rural and urban areas in Minia governorate

\subsection{Subjects}

The study involved a convenience sample of 120 women. The subjects were randomly divided into experimental and control groups, each group consisted of 60 women attending the study setting during the study period, agree to participated in the study and having the inclusion criteria. The inclusion criteria were woman aged range between 20-60 years, married, no hysterectomy, no history of cervical cancer.

\subsection{Tools of data collection}

Tools of data collection used in this study were consisted of three tools:

1) A Self-Administered Questionnaire: It was designed by the researcher to collect data related to women's socio- demographic characteristics such as age, marital status, level of education, occupation and family income, history of previous marriage, history of sexually transmitted diseases, smoking, tendency to use contraceptives, Pap test history and family history of cancer ....etc.

2) Knowledge assessment tool

It was developed by the researcher after extensive literature review and it include thirty seven multiple choice questions concerned with women's' knowledge regarding cervical cancer and its screening.

Scoring System

Answers obtained from the women related to knowledge were scored and calculated. According to the answers, their responses were evaluated using the model key answer sheet prepared by the researcher. Each question was ranged from 0-1 grade. Whereas, correct and complete answer scored 1 grade and score zero for incorrect, incomplete answer and unknown response. The total score of the questionnaire for knowledge was 37 grades .Based on women response for knowledge question, answer above 67\%, 33- 
$67 \%$ and less than $33 \%$ of knowledge question was levelled as good, satisfactory and poor knowledge respectively.

3) CPC-28 Questionnaire

CPC-28 Questionnaire which have six domains based on Health Belief Model including perceived susceptibility or women' opinion about chances of getting cervical cancer, perceived severity and complications of cervical cancer, perceived benefits of cervical cancer preventive behaviors, perceived barriers and selfefficacy in performing (Urrutia, 2009). The constructs of the perceived susceptibility (6 questions), perceived severity (4 questions), perceived benefits (5questions), perceived barriers (10 questions), perceived self-efficacy (5 questions). Cronbach's coefficient alpha for CPC-28 Questionnaire is 0.735 and inter-item correlation is 0.083 .

Health beliefs were assessed by the 5-item Likert scale (1 strongly disagree to 5 very agree). So the score range of each question in the perceived susceptibility, severity, benefits, barriers and selfefficacy was between 1to 5. For the barriers, the reversed scoring was used. The total score of each component was calculated for all subject in order to assess the effect of training on women believes before and after counseling.The total scores was 150 divided into two categories. Scores from 75 - 150 referred to positive beliefs while scores $(<75)$ referred to negative beliefs.

\subsection{Post counselling follow-up}

Evaluating the changes in health beliefs and practices toward preventive measures of cervical cancer was assessed post counseling using questions having "done" or "Not done" response.

\subsection{Pilot study}

A pilot study was conducted on ten woman selected from the same study setting to check and make sure the clarity, applicability to identify any difficulties with their application, and to determine the time needed for completion of the tools. Modification of the tools was done according to pilot results to reach to the finalized form. Subjects who shared in the pilot study were not included.

\subsection{Procedures}

An official permission was obtained to conduct the study. The researchers introduce themselves and briefly explained the nature and the purpose of the study to the approached ones who full fill the inclusion criteria in the sample and each meeting took about 10-15 minutes. All women were informed that their participation is voluntary. After obtaining the orally acceptance of women to participate in the study, the researcher provided them an overview and clarification about the assessment sheet question. The Self Administered Questionnaire and knowledge Assessment Sheet (pretest)were distributed to each woman in the two groups. Also, the required explanations and clarifications were done according to the women' questions.

Counseling was done in the intervention group .Individualized and grouped counseling strategies were used. Two counseling sessions each one was between 30-40 min duration. It included a combination of lectures, group discussion, questions and answers. The first session begin with greeting to establish a verbal communication with women and then an introduction about the cervical cancer, prevalence and the symptoms. In addition causes, risk factors to increase the susceptibility and perceived severity. In order to reduce the perceived barriers and increase the perceived benefits ,the second session included counseling about prevention, benefits Pap smear test and its complications and how it can be prevented, with an emphasis on screening methods especially vualval selfexamination ,Papanicolau smear test as the common screening method .Educational pamphlets were given to the women at the end of the last session. Moreover information on the cost of the test, and where and how to access the test was also provided in order to reduce the perceived barriers and increase the perceived benefits in the Pap smear test.

\subsection{Post counselling follow-up}

One month after counseling, the researchers were contacted with the women and Pap smear test was reminded. Evaluating the changes in knowledge, believes and practices toward preventive measures of cervical cancer was carried for two months aftertheendofcounselingsessions, bothgroupswereinvitedforfollowup, andthepost-

testquestionnairewascomplet-

ed.Duringthisperiod,thecontrolgrouponly received the routine care. Both groups were examined and compared before the intervention, and two months after the end of intervention. For ethical issues and non-deprivation of the control group from the benefit s of research, after the end of intervention and follow-up, all the contents related to the cervical cancer screening were taught to the women in control group and educational pamphlets were given to them.

Table 1:Distribution of the Women Regarding to Their Socio Demographic Characteristics

\begin{tabular}{|c|c|c|c|c|c|c|}
\hline \multirow{2}{*}{ Demographic characteristics } & \multicolumn{2}{|c|}{ Intervention } & \multicolumn{2}{|c|}{ Control } & \multirow{2}{*}{$\mathrm{X}^{2}$} & \multirow{2}{*}{ P. Value } \\
\hline & No. & $\%$ & No. & $\%$ & & \\
\hline \multicolumn{3}{|l|}{ Age } & \multicolumn{2}{|l|}{1} & \multirow{4}{*}{$\begin{array}{l}.01 .3 \\
1\end{array}$} & \multirow{4}{*}{0.911} \\
\hline - $\quad 20-<25$ & 15 & 25 & 11 & 18.3 & & \\
\hline - $\quad 25-45$ & 32 & 53.3 & 41 & 68.3 & & \\
\hline - $\quad>45$ & 13 & 21.7 & 8 & 13.3 & & \\
\hline \multicolumn{7}{|l|}{ Age at married } \\
\hline - $\quad<20$ & 10 & 16.7 & 7 & 11.7 & \multirow{4}{*}{1.861} & \multirow{4}{*}{0.173} \\
\hline - $\quad 20-25$ & 29 & 48.3 & 25 & 41.7 & & \\
\hline - $26-30$ & 15 & 25 & 19 & 31.7 & & \\
\hline - $\quad>30$ & 6 & 10 & 9 & 15 & & \\
\hline \multicolumn{7}{|l|}{ Years of Married } \\
\hline - $\quad<$ one year & 15 & 25 & 10 & 16.7 & \multirow{4}{*}{.181} & \multirow{4}{*}{0.670} \\
\hline - $\quad 1-5$ & 16 & 26.7 & 17 & 28.3 & & \\
\hline - $6-10$ & 20 & 33.3 & 29 & 48.3 & & \\
\hline - $\quad>10$ & 9 & 15 & 4 & 6.7 & & \\
\hline \multicolumn{7}{|l|}{ Level of education: } \\
\hline - Illiterate & 7 & 11.7 & 9 & 15 & \multirow{4}{*}{.001} & \multirow{4}{*}{0.976} \\
\hline - Basic & 3 & & 6 & 10 & & \\
\hline - Secondary & 41 & 68.3 & 31 & 51.7 & & \\
\hline - University & 9 & 15 & 14 & 23.3 & & \\
\hline \multicolumn{7}{|l|}{ Occupation : } \\
\hline - Working & 42 & 30 & 23 & 38.3 & \multirow{2}{*}{.918} & \multirow{2}{*}{0.338} \\
\hline House wife & & 70 & 37 & 61.7 & & \\
\hline
\end{tabular}

Table 1, shows that the majority of the studied sample finds that $53.3 \%, 68.3 \%$ was aged 25 to 45 years old and $25 \%, 18.3 \%$ was aged $20<25$ years old in intervention and control groups respectively, There was no significant difference in the age of both groups $(\mathrm{P}=0.911)$. As regards to the age at marital, it was found that $48.3 \%, 41.7 \%$ married at age $20-25$ years old ,25\%, $31.7 \%$ was married at age 26-30 years old in intervention and control groups respectively, There was no significant difference in the married age of both groups $(\mathrm{P}=0.173)$. Also this table shows that $33.3 \%, 48.3 \%$ of the women had married from 6 to 10 years in the intervention and control groups respectively. As regarding level of education present findings showed that $68.3 \%$ and $51.7 \%$ in intervention and control groups, had secondary education respectively. Majority of women were housewives. Homogeneity of demographic variables is shown in (Table 1).

Table 2:Frequency Distribution of the Study Sample According to Reproductive Health

\begin{tabular}{lllllll}
\hline \multirow{2}{*}{ Items } & \multicolumn{7}{c}{ Intervention Control } & \multirow{2}{*}{$\mathrm{X}^{2}$} & \multirow{2}{*}{ P.Value } \\
& No & $\%$ & No & $\%$ & & \\
\hline $\begin{array}{l}\text { Menstrual history } \\
\text { Regular }\end{array}$ & 52 & 86.7 & 45 & 75 & & \\
\hline
\end{tabular}




\begin{tabular}{llllll}
\hline Irregular & 8 & 13.3 & 15 & 25 & 1.8070 .071 \\
Genital tract infection & & & & & \\
Yes & 22 & 36.7 & 26 & 43.3 & \\
No & 38 & 63.3 & 34 & 56.7 & 1.6330 .102 \\
Methods of Contraceptive used & & & & & \\
Pills & 24 & 40 & 26 & 43.3 & \\
IUD & 19 & 31.7 & 21 & 35 & \\
Hormone injection & 10 & 16.7 & 9 & 15 & 1.6960 .09 \\
Safe period & 7 & 11.7 & 4 & 6.7 & \\
\hline
\end{tabular}

Regarding reproductive health history, the results revealed that the most of the intervention and control group $(86.7 . \%, 75)$ had regular menstruation respectively. More than half $(63.3 \%$ and $56.7 \%)$ of the intervention and control group had no genital tract infection. More than one third of the intervention and control group (40.0\% and $43.3 \%$ ) had used oral contraceptive methods, $(31.7 \%$, $35 \%$ ) had used IUD method respectively (Table 2).

Table 3:Mean Scores of Knowledge of the Study Sample Before and After Two Months of Counseling

\begin{tabular}{|c|c|c|c|c|c|c|c|c|}
\hline Variables & $\begin{array}{l}\text { Before counselling } \\
\text { Intervention } \mathrm{N}=60 \\
\text { mean } \pm \mathrm{SD}\end{array}$ & $\begin{array}{l}\text { Control } \mathrm{N}=60 \\
\text { mean } \pm \mathrm{SD}\end{array}$ & t. & P. value & $\begin{array}{l}\text { After counselling } \\
\text { Intervention } \mathrm{N}=60 \\
\text { mean } \pm \mathrm{SD}\end{array}$ & $\begin{array}{l}\text { Control } N=60 \\
\text { mean } \pm \text { SD }\end{array}$ & t. & value \\
\hline Risk factor & $3.91 \pm 1.318$ & $3.61 \pm 1.584$ & 1.127 & .262 & $8.58 \pm 1.21$ & $3.80 \pm 1.32$ & 20.63 & $0.001 * *$ \\
\hline Symptoms & $1.40 \pm .494$ & $1.26 \pm .445$ & 1.552 & .123 & $3.20 \pm .731$ & $1.28 \pm .454$ & 17.23 & $0.001 * *$ \\
\hline Methods of diagnosis & $2.73 \pm 1.006$ & $2.50 \pm 1.295$ & 1.102 & .273 & $5.21 \pm .865$ & $2.56 \pm 1.079$ & 14.83 & $0.001 * *$ \\
\hline Prevention & $4.66 \pm .950$ & $4.46 \pm 1.096$ & 1.067 & .288 & $10.85 \pm 1.44$ & $4.53 \pm 1.32$ & 24.96 & $0.001 * *$ \\
\hline Pap smear and HPV vaccination & $1.28 \pm .555$ & $1.26 \pm .445$ & .181 & .856 & $2.51 \pm .503$ & $1.283 \pm .490$ & 13.58 & $0.001 * *$ \\
\hline Total & $13.98 \pm .2 .317$ & $13.09 \pm .2 .42$ & 1.615 & .109 & $30.36 \pm 2.635$ & $13.46 \pm 2.197$ & 38.14 & $0.001 * *$ \\
\hline
\end{tabular}

*Significant, **H Significant

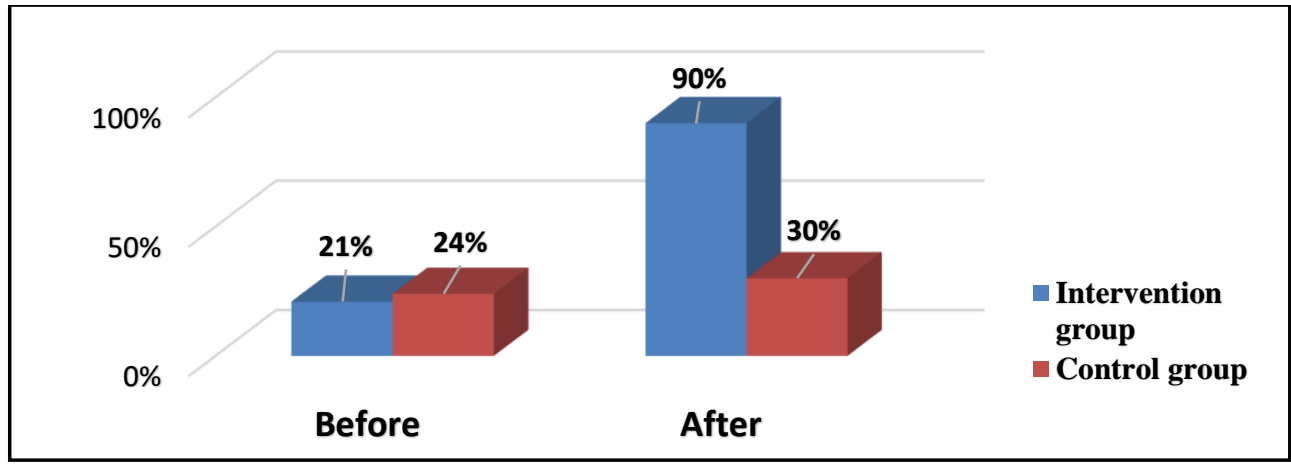

Fig. 1: Distribution of the Women by Their Knowledge Regarding to Pap-Smear Before and After Counseling.

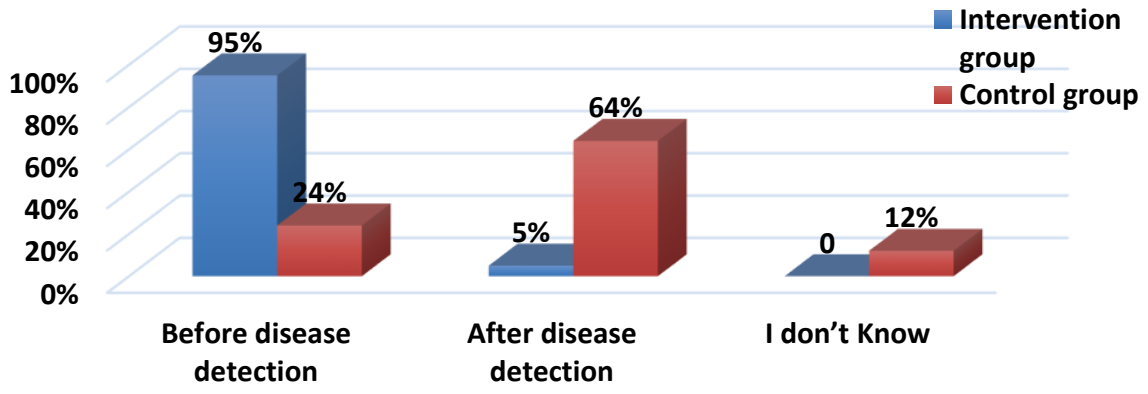

Fig. 2: Distribution of the Women by Their Knowledge about Time for Pap smear After Counseling.

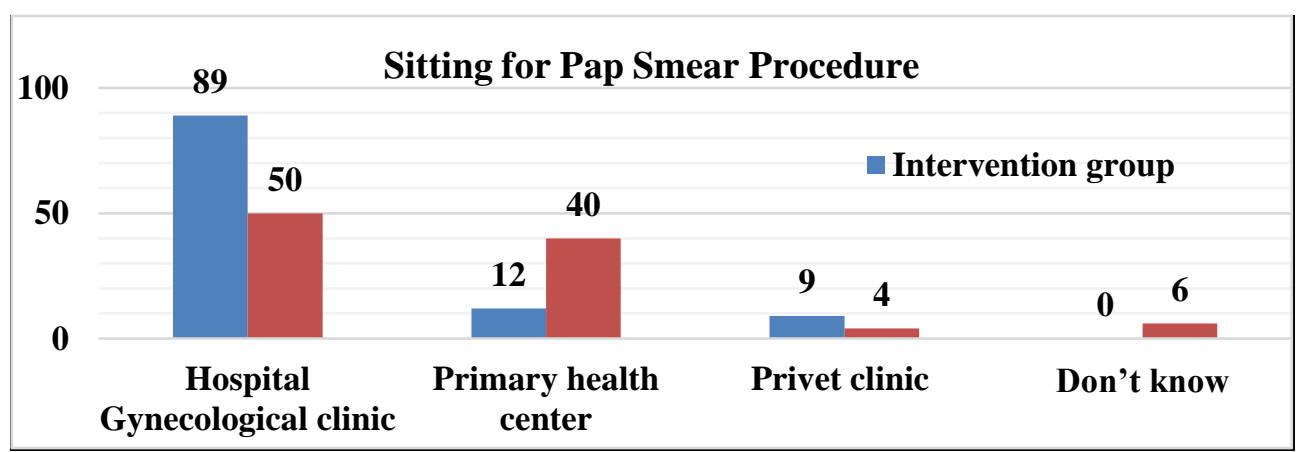

Fig. 3: Distribution of the Women by Their Knowledge about Sitting for Pap smear and HPV Vaccination after Counseling.

As shown in Table 3.highly statistically significant difference was found between groups $(\mathrm{P}<0.001)$ regarding to mean scores knowledge of risk factors, symptoms, methods of diagnosis, pap smear and HPV vaccination before and after two months of counselling.
Regarding women's knowledge about Pap smear test. Figure 1 showed that before counseling just $(21 \%)$ women in intervention group and (24\%) women in control group had little information about Pap smear test. After the intervention $90 \%$ of intervention group women answer to this question "do you have information 
about pap smear" was changed to yes as compared to $30 \%$ of women in control group.

Regarding the Time for Pap smear, figure 2 showed that, 95\% of women said before disease detection, while $5.0 \%$ after disease detection in intervention group as compared to $24 \%, 64 \%$ in the control group respectively.
As regarding the women knowledge about sitting for Pap smear procedure, figure 3 showed that, $89.0 \%$ of the women in intervention group said in the hospital (Gynecological clinic), only $12.0 \%$ had knowledge done in primary health center as comparedto50\%, $40 \%$ in the control group respectively.

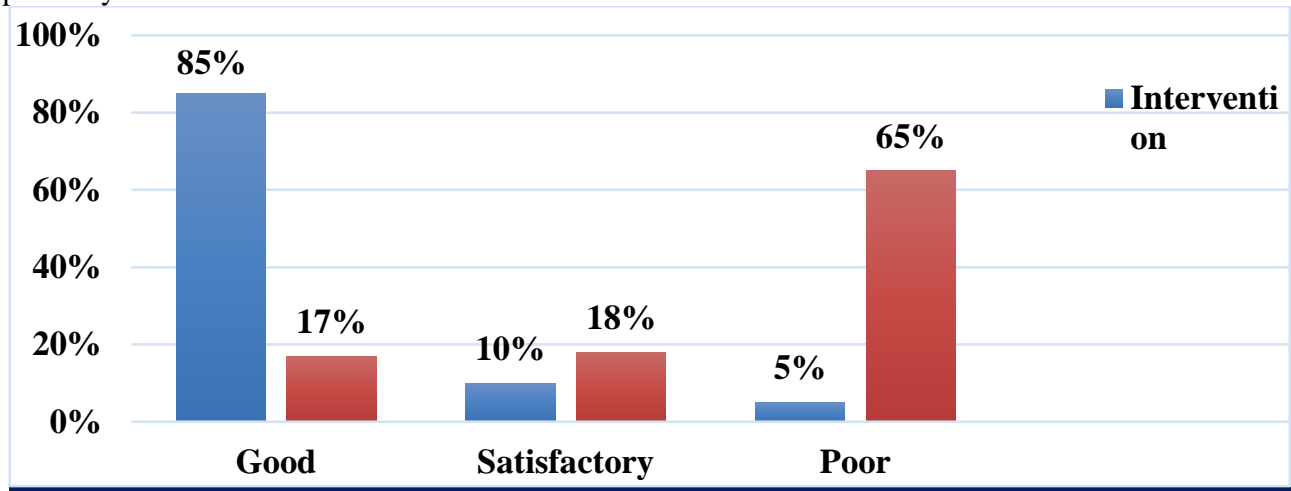

Fig. 4: Percent Distribution of the Women by Their Total Knowledge Regarding to Cervical Cancer after Counseling.

Table 4:Comparison of Health Belief Model Constructs in the Intervention and Control Groups Before and After Two Months of Counselling

\begin{tabular}{llllc}
\hline Variables & $\begin{array}{l}\text { Before counselling } \\
\text { Intervention N=60 } \\
\text { mean } \pm \text { SD }\end{array}$ & $\begin{array}{l}\text { Control N=60 } \\
\text { mean } \pm \text { SD }\end{array}$ & $\begin{array}{l}\text { P.value } \\
\text { Intervention N=60 } \\
\text { mean } \pm \text { SD }\end{array}$ & $\begin{array}{l}\text { Control N=60 } \\
\text { mean } \pm \text { SD }\end{array}$ \\
\hline Perceived susceptibility to cervical cancer & $14.516 \pm 1.610$ & $14.266 \pm 1.830$ & 0.315 & $22,833 \pm 29.720$ \\
Perceived severity of cervical cancer & $14.75 \pm 1.998$ & $14.333 \pm 1.704$ & 0.108 & $17.916 \pm 5.672$ \\
Perceived benefits of Pap test & $15.033 \pm 2.469$ & $14.766 \pm 2.102$ & 0.159 & $18.483 \pm 11.785$ \\
Perceived barriers of Pap test & $43.466 \pm 41.861$ & $38.333 \pm 39.006$ & 0.296 & $20.150 \pm 30.120$ \\
Self-efficacy & $11.450 \pm 7.768$ & $12.056 \pm 18.154$ & 0.824 & $17.83 .516 \pm 30.120$ \\
\hline
\end{tabular}

*Significant, **H Significant.

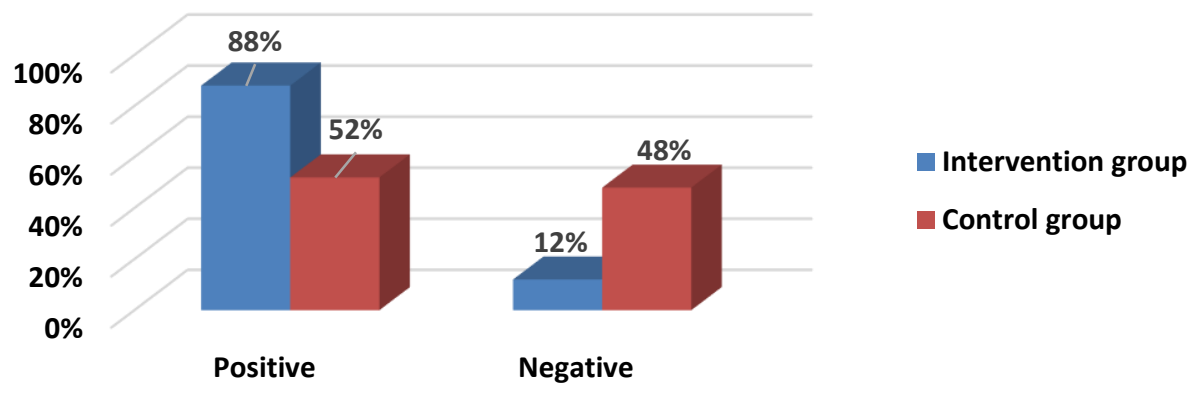

Fig. 5: Distribution of the Women by Their Total Beliefs Regarding Cervical Cancer after Counseling.

Table 5:Percent Distribution of the Women's Beliefs about Factors Help Early Diagnosis of Cervical Cancer after Counseling

\begin{tabular}{|c|c|c|}
\hline \multirow{2}{*}{ Items } & \multicolumn{2}{|c|}{ Intervention $(\mathrm{N}=60)$} \\
\hline & No & $(\%)$ \\
\hline Higher educational level for women & 52 & $87 \%$ \\
\hline Family history of the disease & 31 & $52 \%$ \\
\hline Priorities of health of the women & 45 & $75 \%$ \\
\hline Awareness for early detection of disease & 40 & $67 \%$ \\
\hline Mass media & 20 & $33 \%$ \\
\hline
\end{tabular}

Regarding the level of total knowledge after counseling, figure (4) showed that $86 \%$ of the women in the intervention group had good knowledge compared to only $17 \%$ of the control group, while more than two third $(65 \%)$ in the control group had poor knowledge compared to only $5 \%$ of the intervention group.

Table 4,comparethemeanscoresofHealthBelief Model constructs before and after the counseling in both groups, and the results have been shown that after the counseling, the mean score of perceived susceptibilityininterventiongroupandcontrolgroupwasreduced $(\mathrm{P}<0.04)$.Themeanscoreofperceivedseverity and perceived benefits in intervention and control groups were also increased, but the increase demean score in the intervention group was higher. The mean score of perceived barriers were reduced in two groups, but the decrease was significantly higher in the intervention group $(\mathrm{P}<0.004)$.
Regarding to total beliefs two month after counseling, figure (5 ) showed that $88 \%$ of the women in the intervention group had positive beliefs compared to only $52 \%$ of the control group, while less than half $(48 \%)$ of the women in the control group had negative beliefs compared to only $12 \%$ of the intervention group.

Mutual response

Table 5: Represents the women's beliefs about factors help early diagnosis of cervical cancer after counseling. Results of the study revealed that $87 \%$ from the study sample higher educational level for women and history of the disease in the family. While only $20 \%$ of the woman the mass media for early detection of the cervical cancer.

As regarding after counseling cervical cancer protective practice in both groups, table (6) showed that a significant difference was observed related to Pap smear $(\mathrm{p}=.001)$. Also this table shows a highly statistical significant difference was observed for take vac- 
cine, vaginal hygiene care, Self-examination for vulva, use of contraceptive as prescribed and diet rich in fresh vegetables and fruits $(\mathrm{p}=.0001)$.

Table 6:Percent Distribution of the Women's by their protective Practices from Cervical Cancer after Counseling

\begin{tabular}{|c|c|c|c|c|c|c|}
\hline Practice & $\begin{array}{l}\text { Intervention } \\
\text { Done No }(\%)\end{array}$ & $\begin{array}{l}\text { Not done No } \\
(\%)\end{array}$ & $\begin{array}{l}\text { Control } \\
\text { Done No (\%) }\end{array}$ & $\begin{array}{l}\text { Not done No } \\
(\%)\end{array}$ & $X^{2}$ & P.value \\
\hline Pap smear & $24(40)$ & $36(60)$ & $8(13.3)$ & $52(86)$ & 10.818 & $0.001 * *$ \\
\hline Self-examination for vulva & $35(58.3)$ & $25(41.7)$ & $8(13.3)$ & $52(86)$ & 26.201 & $.0001 * *$ \\
\hline Vaginal hygiene care & $47(78.3)$ & $13(21.7)$ & $11(18.3)$ & $49(81.7)$ & 42.88 & $.0001 * *$ \\
\hline Treating of genital infections & $39(65)$ & $21(35)$ & $12(20)$ & $48(80)$ & 24.652 & $.0001 * *$ \\
\hline Use contraceptive as prescribed & $51(85)$ & $9(15)$ & $18(30)$ & $42(70)$ & 36.626 & $.0001 * *$ \\
\hline diet rich in fresh vegetables and fruits & $50(83.3)$ & $10(16.7)$ & $18(30)$ & $42(70)$ & 34.462 & $.0001 * *$ \\
\hline
\end{tabular}

*Significant, **H Significant.

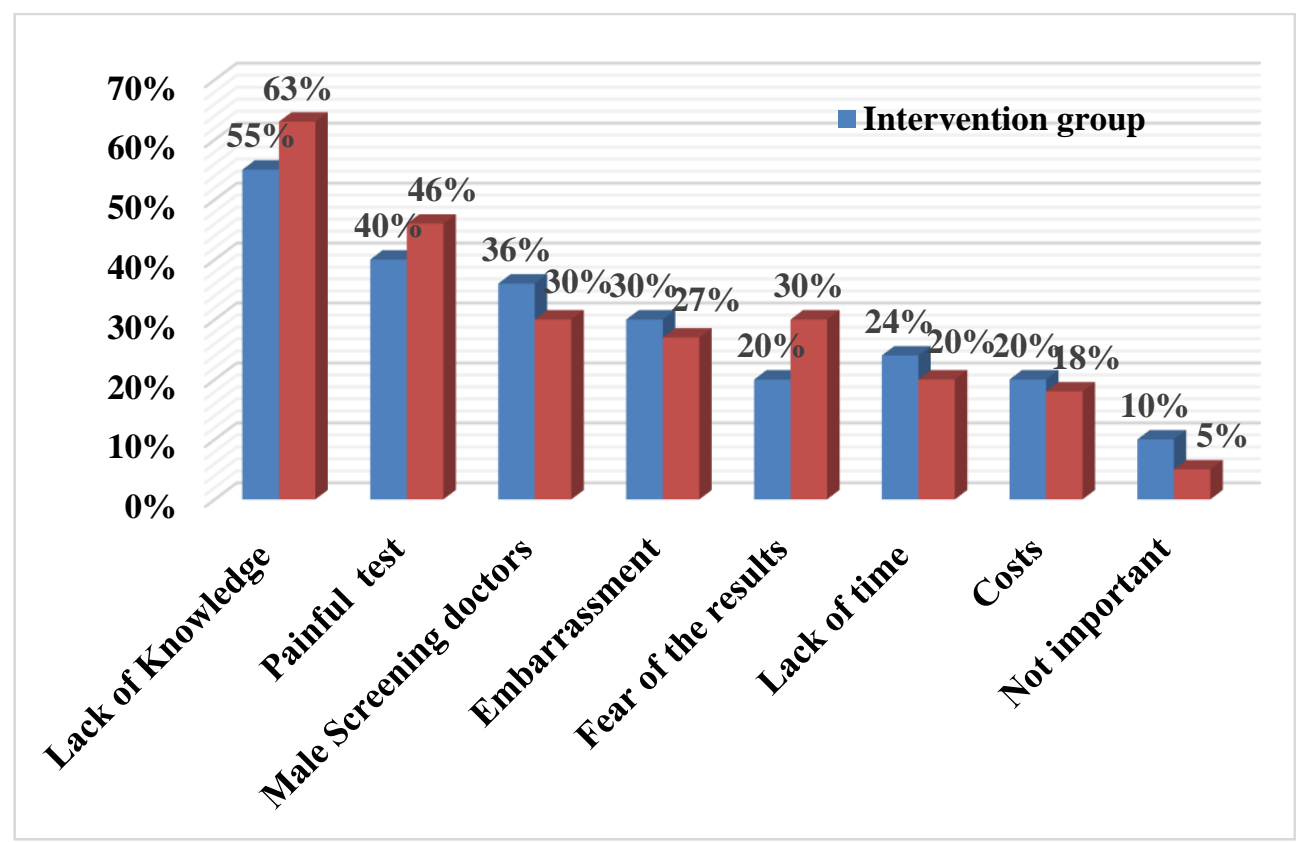

Fig. 6: Percent Distribution of the Sample by Their Barriers to Pap smear Test.

Figure (6) showed that the women barriers to Pap smear test included the lack of knowledge, painful test, and male screening doctor fear of the results ,embarrassment ,costs, and lack of time.

\section{Discussion}

Cervical Cancer of the cervix is the second most common cancer among women worldwide. Estimated 529,409 new cases, $86 \%$ of the cases occur in developing countries, representing $13 \%$ of female cancers. Cervical cancer is the $8^{\text {th }}$. Most frequent cancer among women between 15 and 44 years of age(Khalid H., 2009, Dania AJ, Tasnim H., 2010).

The present study was set to test the hypotheses that women's knowledge regarding cervical cancer and its screening means score will be significantly higher post counselling, counselling will be aid to change the false beliefs and enhance health practice for screening of cervical cancer. The study results demonstrated significant improvements in all these parameters, which lead to acceptance of the hypotheses. According to the current study finding, there was no statistically significant difference in regarding the age of both groups $(\mathrm{P}=0.911)$. As regard to the age at marital, there is no significant difference was found in both groups $(\mathrm{P}=0.173)$. As regarding level of education present findings showed that $68.3 \%$ and $51.7 \%$ in intervention and control groups, had secondary education respectively. Majority of women were housewives. Homogeneity of demographic variables is shown in (Table 1). More than one third of the intervention and control group had used oral contraceptive methods and experiences genital tract infection which may put them at risk for cervical cancer.
Also, the results of the present this results go on line with the results with the study done by (Soliman, Badawy, and Fouad 2017). Increasing the women's awareness is an important first step to attain a lower incidence and mortality. In parallel with an increased awareness, the national health care system should facilitate and encourage early diagnosis and therapy .As regarding mean scores of knowledge in the intervention and control groups, results of current study revealed that, before intervention majority of both groups had little knowledge about risk factors, signs and symptoms, methods of diagnosis and prevention of cervical cancer while after intervention there are highly statistical significant improvement in women knowledge was observed in the intervention group as compared to control group $(\mathrm{P}=0.0001)$, This finding is consistent with the results of the study done by Masoume, etal(2016) andShobeiri F., (2016)they mentioned that before intervention majority of both groups didn't know about signs and symptoms of cervical cancer and which is consistent with the findings from (Issah et al., 2011). Furthermore the lack of knowledge demonstrated from most of the studies is similar to the findings by James (2011) which showed that majority of the respondents (51.6\%) were not aware of cervical cancer screening.

Despite strong evidence that the Pap smear test is an appropriate method for increasing early intervention opportunities and decreasing the incidence and mortality associated with cervical cancer (WHO., 2013), many women in low-middle income countries have not availed themselves for screening. In this study before intervention less than one quarter of women in both groups had little information about Pap smear test .This might be explained by poor knowledge about cervical cancer will affect women's manner 
to neglect Pap smear and screening service. This finding is go on line with the results of the study done in Malaysia that showed that there is a lack of knowledge on the Pap smear test on women aged 21-56 years who never experienced the Pap smear test (Wong et al., 2009). The participants had the assumption that Pap smear test was used to identify existing cervical cancer. Many studies suggest that women with low knowledge of cervical cancer have lower rates of screening than women who have more knowledge. Reis et al., et al., (2012) mentioned that lack of knowledge about the disease, and preventive behavior are important factors that prevent women from using the screening services.

After the intervention majority (90\%) of the women answer to this question "do you have information about pap smear" was changed to yes as compared to (30\%) of women in control group. Counseling helps to reduce anxiety as well as protect the rights of the individual to health information. Total knowledge of women regarding cervical cancer and its screening revealed that majority of the women in the intervention group had good knowledge compared to less than one fifth of control group. With increasing women's level of knowledge and correcting their wrong information, tendency to participate in cervical cancer screening will raise.

Health Belief Model (HBM) has been considered to be one of the most representative ones due to its effectiveness in explaining change and maintenance of health behavior. Results of the current study indicated that after the intervention, the mean score of all components of HBM increased significantly compared to preintervention but the increase was significantly higher in the intervention group. The significant difference between two groups after study,could be related to the effect of group counseling. Our findings are consistent with results of the study done by Yakhforoushha et al., (2009),they assessed the effect of training on the voluntary health workers' knowledge and attitude regarding Pap test using HBM. Study done by Shobeirietal., 2016 and Parsa, 2017)also mentioned that after intervention they observed significant differences in all variables of HBM in intervention group and no significant differences in control group.

The construct of the perceived susceptibility in this study showed that the susceptibility of the woman toward the health problem associated with the belief inbeing at risk, even in the absence of symptoms, would lead to participation in the screening programs such as cervical cancer screening .Similarly, (Pir zadeh and Mazaheri, 2012, and Shojaeizadeh et al., 2011) found increased perceived susceptibility after intervention .However, Tahmasebi et al., (2016), revealed no effect on the perceived susceptibility after the educational intervention.According to our findings, after intervention a significant increase was seen in awareness and the higher positive beliefs about perceived benefits of preventive health practices, susceptibility, severity, health motivationand reduced the barriers of pap smearthis can influence women's willingness to take preventive test and higher participation in regular Pap smear test. These results are consistent with other study (Shobeiriet al., 2016,Reis et al., 2012; Mousavi et al., 2013; Shobeiri and Nazari, 2014).

Moreover many studies done byRakhshani et al., (2013), Tahmasebi et al., (2016), Pirzadeh and Mazaheri, (2012), and Shojaeizadeh et al., (2011), are also in agreement with the results of the current study .The perceived self-efficacy in both groups showed no significant difference before the intervention, but it was increased after the intervention. The increase in self-efficacy was significantly higher in the intervention group compare to the control group, this consistence with the results of study done by Karimi et al., (2009).

The Women's beliefs about factors help early diagnosis of cervical cancer after counseling, higher educational level, priorities of health of the women and awareness for early detection of disease are important factors for motivating the women to carry early detection procedures of the cervical cancer. This result is similar to the findings by Soliman, et al., (2017). The importance of educational level on knowledge about cervical cancer has been stated in many studies (Tehranian et al., 2010).Moreover study done by Lee et al., (2013) mentioned that women with lower educational levels and lower household income were less likely to be screened.

Regarding protective practice after counselling from cervical cancer a high significant was observed related to Pap smear $(\mathrm{p}=.01)$. Thus, increasing the awareness of women on regularity of Pap smear test is essential. A highly statistical significant observed regarding self-examination for vulva, vaginal hygiene care, treatment of genital tract infections, use of contraceptive as prescribed and diet rich in fresh vegetables and fruits $(p=.001)$. This results consistence with results of the study done by Soliman, et al., (2017)but no statistical significant in relation to self-examination for vulva may be due to the psychological fear of the impact of positive test on their physical and social life which in agreement with a study conducted in the western region of Saudi Arabia(Bondagji et al., 2013).

According to our study; willingness of women for the cervical cancer screening was found improvement in intervention group even after having knowledge of the cervical cancer and its prevention as compared to control group which was consistent with the study done by (Mulatu, et al 2017).FurthermorePapa et al., (2009) studied the effect of education on the knowledge, concern and desire of 50 women who were eligible to do Pap smear. They reported that $77 \%$ of the participants were encouraged to do Pap test after intervention. Poor knowledge about cancer will affect women's manner to neglect Pap smear and screening services. This might be because of lack of information, education and communication regarding cervical Cancer and Cancer screening in public health programs.

In this study the most important barriers to Pap smear test in this study for the women were the lack of knowledge and painful test followed by male screening, embarrassment and fear of the results. This results agreement with the results of the study done by Anyebe, et al., (2014) and ccontradict with Mfuh and Lukong (2016)they revealed that majority of the women said the cost implication of screening was a barrier. While a qualitative study done by Fort, et al., (2011) among women in rural Malawi revealed that, the major barrier to seeking preventive screening was low knowledge level. In addition study done by Parsa, et al., (2017) revealed that lack of laboratory facilities and travelling to city for test in gare the most important barriers to Pap smear test for the rural women. While A study done by Ibrahim,Owoeye and Kalada (2013) at Niger revealed that, half of the respondents, considered themselves healthy and did not see any reason to subject themselves to any form of cervical cancer screening. This variation might be due to the level of knowledge, understanding difference to cervical cancer concept .In addition fear from exposure of private parts to male doctors as a major reason for lack of screenings. Males screening women has been found to be a barrier for screening. This implies that, if the health personnel's doing the screening are females, women will feel freer to go for the screening.

Inadequate public health education, lack of patient-friendly health services, sociocultural health beliefs, gender roles, and personal difficulties were the most salient barriers to screening. Furthermore study by Oyedunni and Opemipo (2012) at Ibadan, Nigeria found that, reasons for not utilizing screening services include; lack of time followed by fear of the result, then lack of awareness of where the test could be done then cost consideration and not knowing about the test. Thus the need to intensify effort towards improving the right knowledge among women about cervical cancer screening.

Conclusion

The findings of the current study focus on the important of counselling about cervical cancer and its screening on improving women's knowledge, changing beliefs and enhance health practice for screening of cervical cancer. Based on the findings of the present study, it can be concluded that, there was a highly statistical significant improvement in women knowledge was observed and the 
higher positive beliefs about perceived benefits of preventive health practices, susceptibility, severity, health motivation and reduced the barriers of pap smear this can influence women's willingness to take preventive test and higher participation in regular Pap smear testin the intervention group .The most commonly barriers to screening cited in our study are lack of knowledge, painful test, male screening doctors, embarrassment and fear of the results followed by costs, and lack of time.

\section{Recommendations}

Based on the study findings the following recommendations are suggested:

1) Women should be encouraged to take responsibility for their own health and be active participants in the screening program.

2) More educational intervention is needed to encourage adherence to routine cancer screening with raising women's awareness about cervical cancer

3) Health professionals provide counseling sessions for women about $\mathrm{t}$ screening programs.

4) The barriers to Pap smear test are considered by the health authorities in order to overcome barriers of cervical cancer screening.

5) Integrate cervical cancer prevention strategies with other reproductive health services at all level of health care delivery system.

\section{References}

[1] Elamurugan S, Rajendran P, Thangamani S. (2016): Cervical cancer screening: Awareness, attitude, and practice of Indian women. Tropical Journal of Medical Research. 2016; 19: 426.https://doi.org/10.4103/1119-0388.172062.

[2] American Cancer Society (2013). Cervical Cancer: Prevention and Early Detection. American Cancer Society.

[3] Reis N, Bebis H, Kose S, et al (2012): Knowledge, behavior and beliefs related to cervical cancer and screening among Turkish women. Asian Pacific J Cancer Prev, 13, 146370.https://doi.org/10.7314/APJCP.2012.13.4.1463.

[4] Wong LP, Wong YL, Low WY, Khoo EM, Shuib R (2009): Knowledge and awareness of cervical cancer and screening among Malaysian women who have never had a Pap smear: A qualitative study. Singapore Med J 50: 49-53.

[5] World Health Organization (3013a): WHO Guidance Note Comprehensive Cervical Cancer Prevention and Control. A Healthier Future for Girls and Women. Geneva, Switzerland: World Health Organization; 2013. Available from: http://apps.who.int/iris/bitstream/10665/78128/3/9789241505147_e ng.pdf. Accessed October 21, 2014.

[6] Ghahramaninasab P, Thanasi M, Farshbafkhalili A, GHanbari S (2011): Factors associated with cervical cancer screening in women referred to health centers of Tabriz in 2011-2012. IJOGI, 16, 15-24.

[7] Khodakarami N, Farzaneh F, Yavari P, et al (2013): New cervical cancer screening program for low-risk women in Iran. IJOGI 17, 8 17.

[8] Coskun S, Can H, Turan S (2013): Knowledge about cervical cancer risk factors and Pap smear testing behavior among female primary health care workers: a study from South Turkey. Asian Pac J Cancer Prev, $\quad 14, \quad 6389$ 92.https://doi.org/10.7314/APJCP.2013.14.11.6389.

[9] Urrutia MT (2009). Development and testing of a questionnaire: beliefs about cervical cancer and Pap test in Chilean women.

[10] Gacia F, Berek J, Miller C, Elkas J (2012): Intraepithelial disease of the cervix, vagina, and vulva. Berek and Novak's Gynecology, Vol. 2, Philadelphia: Williams and Wilkins, pp 112-8.

[11] Zarchi MK, Behtash N, Chiti Z, et al (2009): Cervical cancer and HPV vaccines in developing countries. Asian Pac J Cancer Prev, 10, 969-74.

[12] Arabaci Z, Ozsoy S (2012): The pap-smear test experience of women in Turkey: A qualitative study. Asian Pac J Cancer Prev, 13, 5687-90.https://doi.org/10.7314/APJCP.2012.13.11.5687.

[13] Getahun F, Mazengia F, Abuhay M, et al (2013): Comprehensive knowledge about cervical cancer is low among women in North- west Ethiopia. BMC Cancer, 13, 2.https://doi.org/10.1186/14712407-13-2.

[14] Matthews AK, Li CC, Ross N, et al (2013): Breast and cervical cancer screening behaviors of African American sexual minority women. $J$ Gen Pract, 1, 2.https://doi.org/10.4172/2329$\underline{9126.1000107}$.

[15] Nessa A, Hussain MA, Rashid M, et al (2012): Role of print and audiovisual media in cervical cancer prevention in Bangladesh. Asian Pac $J$ Cancer Prev, 14, 31317.https://doi.org/10.7314/APJCP.2013.14.5.3131.

[16] Khatibi M, Rasekh HR, Shahverdi Z (2014): Cost-effectiveness evaluation of quadrivalent human papilloma virus vaccine for hpvrelated disease in iran. Iranian J Pharmaceutical Res, 13, 225.

[17] Tripathi N, KadamYR, Dhobale RV, Gore AD (2014): Barriers for early detection of cancer amongst Indian rural women. South Asian J Cancer, 3, 122-7.https://doi.org/10.4103/2278-330X.130449.

[18] Jamshidimanesh M, Golian TS, Hosseini A, Shams A, lahoni F (2013): The effect of an educational program on prevention of postpartum depression. Payesh, 12, 619-27.

[19] Farooqui M, Hassali MA, Knight A., (2013): A qualitative exploration of Malaysian cancer patients' perceptions of cancer screening. BMC Public Health, 13, 48.https://doi.org/10.1186/1471-2458-13$\underline{48}$.

[20] Khalid H., (2009): Attitudes, knowledge, and practices in relation to cervical cancer and its screening among women in Saudi Arabia, Saudi Med J; 30(9): 1208-1212.

[21] Dania AJ, Tasnim H., (2010):Prevalence of abnormal cervical cytology among subfertile Saudi women. Available from: http://www.saudiannals.net/article.asp? issn $=02564947$; year $=2010 ;$ volume $=30 ;$ issue $=5$; spage $=397$; epage $=4$ 00 ; aulast $=$ Al-Jaroudi

[22] Tahmasebi R, Hosseini F, Noroozi A (2016): The effect of education based on the health belief model on women's practice about Pap smear test. J Hayat, 21, 80-92.

[23] James John (2011): The Knowledge, Attitude, Practice and Perceived Barriers towards Screening for Premalignant Cervical Lesions Among Women Aged 18years And Above, In Songea Urban, Ruvuma: A dissertation of Master degree of Medicine (Obstetrics and Gynaecology) of the Muhimbili University of Health and Allied Sciences

[24] Masoume, Parisa, and Ghodratollah, (2016): Effects of Group Training Based on the Health Belief Model on Knowledge and Behavior Regarding the Pap Smear Test in Iranian Women: a QuasiExperimental Study, Asian Pac J Cancer Prev, 17 (6), 2871-2876

[25] Issah F, Maree JE, Mwinituo PP (2011): Expressions of cervical cancer-related signs and symptoms. European J OncolNurs, 15, 6772.https://doi.org/10.1016/j.ejon.2010.06.003.

[26] SolimanBadawy and Fouad(2017): Efficacy of counseling for cervical cancer screening

[27] and protective procedures on Saudi women's health beliefs and practice, Journal of Nursing Education and Practice 2017, Vol. 7, No. 2

[28] Shobeiri1 F., TaravatiJavad M., Parsa P., and Roshanaei G., (2016): Effects of Group Training Based on the Health Belief Model on Knowledge and Behavior Regarding the Pap Smear Test in Iranian Women: a Quasi-Experimental Study, Asian Pac J Cancer Prev, 17 (6), 2871-2876.

[29] Lee M, Park EC, Chang HS, et al (2013): Socioeconomic disparity in cervical cancer screening among Korean women: 1998-2010. BMC public health, 13, 553.https://doi.org/10.1186/1471-2458-13553.

[30] Tehranian N, Shobeiri F, Pour FH, et al (2010): Risk factors for breast cancer in Iranian women aged less than 40 years. Asian Pac J Cancer Prev, 11, 1723-5.

[31] Yakhforoushha A, Solhi M, Ebadifard A. (2009): Effects of education via health belief model on knowledge and attitude of voluntary health workers regarding Pap smear in urban centers of Ghazvin. Faculty ofNrsing of Mdwifery Quarterly. 2009; 18(63):25-30.

[32] Parsa, P., Sharifi, F., Shobeiri F., and Karami M., (2017 ): EffectsofGroupCounsellingBasedonHealthBeliefModelon Cervical Cancer Screening Beliefs and Performance ofRuralWomen in Kaboudrahang, Iran, Asian Pac J Cancer Prev, 18 (6), 1525-1530

[33] Shojaeizadeh D, Hashemi SZ, Moeini B, Poorolajal J (2011): The effect of educational program on increasing cervical cancerscreeningbehavioramongwomeninHamadan,Iran: Applying health belief model. JRHS, 11, 20-5.

[34] Pirzadeh A, Mazaheri M (2012): The effect of education on women's practice based on the Health Belief Modelabout pap smear test. Int J Prev Med, 6, 365-72. 
[35] Shabbier F, Nazari M (2014): Age at menopause and its main predictors among Iranian women. Int J FertilSteril, 8, 267-72.

[36] Mousavi SA, Masoumi SZ, Keramat A, et al (2013): Assessment of questionnaires measuring quality of life in infertile couples: a systematic review. J Reproduct Infertility, 14, 110.

[37] Karimi M, GhofraniporF, Heidarnia A (2009): The effect of healtheducationbasedonhealthbeliefmodelonpreventiveactionsofAIDSonaddictinZarandieh.JGuilanUnivMedSci, 18, 64-73.

[38] Bondagji NS, Gazzaz FS, Sait K, et al. (2013): Prevalence of highrisk human papillomavirus infections in healthy Saudi women attending gynecologic clinics in the western region of Saudi Arabia, Ann Saud Medical. 2013; 33(1): 13-17. PMid: 23458934.https://doi.org/10.5144/0256-4947.2013.13.

[39] Papa D, Moore Simas TA, Reynolds M, Melnitsky H. (2009): Assessing the role of education in women's knowledge and acceptance of adjunct high-risk human Papillomavirus testing for cervical cancer screening. J Low Genit Tract Dis. 2009; 13 (2):6671.https://doi.org/10.1097/LGT.0b013e31818a53f0.

[40] Mulatu K, Motma A, Seid M, (2017): Assessment of Knowledge, Attitude and Pratice on Cervical Cancer Screening among Female Students of MizanTepi University, Ethiopia, 2016. Cancer BiolTherOncol. 2017, 1:1.

[41] Anyebe E.E., Opaluwa S.A., Muktar H.M., Philip F. (2014) Knowledge and Practice of Cervical Cancer Screening amongst Nurses in Ahmadu Bello University Teaching Hospital, Shika, Zaria. Research in Humanities and SocSci, 4 (27). [Accessed 25th November 2014].

[42] Mfuh Anita Yafeh and Lukong Christopher Suiye., (2016): Women's Views on Knowledge and Barriers to Cervical Cancer Screening among Women in Kaduna State, Nigeria Greener Journal of Epidemiology and Public Health ISSN: 2354-2381 Vol. 4 (2), pp. 044054, October 2016

[43] Fort V.K. Makin M.S. Siegler A.J. (2011): Barriers to Cervical Cancer Screening in Mulanje, Malawi: A Qualitative Study, https://dx.doi.org/10.2147/PPA.S17317, open access to scientific and medical research, Volume 2011:5 Pages 125-131, [accessed October 25, 2016]

[44] Ibrahim I., Owoeye O., Kalada M., (2013): Cervical cancer screening among female undergraduates and staff in the Niger delta region of Nigeria. Open Journal of Obstetrics and Gynecology, 2013 3, 61-66. Available at http://dx.doi.org/10.4236/ojog.2013.31014, http://www.scirp.org/journal/ojog,[accessed January 24, 2013].https://doi.org/10.4236/ojog.2013.31014.

[45] Oyedunni, S. A., Opemipo, O. M.(2012): Perception and utilization of cervical cancer screening services among female nurses in University College Hospital, Ibadan, Nigeria. The Pan African Medical $J ; 11: 69$

[46] Abedian Z, Darmohamadi M. (2015). The survey of knowledge, attitude and practice of women referred to health centers in Mashhad in papsmeain 2009. Journal of Obstetrics Gynecology and Infertility. 2015; 15: 22-28

[47] KasmaeiP. BabeghbalS, Atrkar Z, Estebsari F, Mehrabian P, KarimiM.The role of HBM in Papsmear of rural women. Journal of Nursing and Midwifery ColegeofOromieh. 2014; 12: 401-8. 